\title{
REDES TRANSFRONTEIRIÇAS NO MERCOSUL
}

\author{
Rogério Haesbaert* \\ Marcelo Santa Bárbara**
}

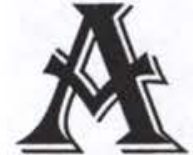

migração de brasileiros para os vizinhos do Prata acelerou-se nas últimas décadas e, mesmo antes da criação do Mercosul, já representava um amplo processo que impunha a organização espacial de conexões de vários tipos, ultrapassando as linhas de fronteira internacional. Se nos anos 70 e 80 a migração rumo ao leste paraguaio foi uma constante, nos anos 90 vieram se somar os fluxos, menos volumosos, mas economicamente relevantes, rumo ao Pampa uruguaio e argentino (Haesbaert e Silveira, 1999).

Este artigo pretende sistematizar dados de uma pesquisa muito mais ampla, em fase final de execução ${ }^{\prime}$, relativos aos fluxos de diversas ordens que se desdobram por sobre as linhas fronteiriças do Brasil com os vizinhos do Mercosul. Estes fluxos - econômicos, culturais e até mesmo políticos, de caráter legal ou ilegal, configuram aquilo que denominamos "redes transfronteiriças".

\section{REDES E FRONTEIRA}

Para falar de redes transfronteiriças precisamos, primeiro, definir o que entendemos por fronteira. Podemos nos referir a três noções distintas de fronteira: a fronteira político-administrativa, para cuja noção - linear - seria mais adequado utilizar o termo limite, limite internacional; a fronteira econômica, área de expansão de novos modos ou formas de produção, como o que ocorre com a difusão da economia capitalista; e a fronteira como fronteira cultural, o "front" de um grupo ou de uma cultura que avança e a "linha de contato" com a cultura que é subjugada².

Os três sentidos de fronteira acima aludidos servem para ser incorporados à nossa designação de redes transfronteiriças. Os migrantes que participam destas redes, ao mesmo tempo que transpõem os limites internacionais, a fronteira política, recriam a fronteira econômica, expandindo a modernização agro-industrial capitalista para novas áreas, e estabelecem uma relação cultural conflitiva com os antigos grupos locais, como o índio ou o camponês descendente de guaranis, no caso paraguaio. Assim, novas relações sociais e novos hábitos culturais vão sendo conflitivamente implantados, levados no bojo da difusão de complexos agro-industriais, como o da soja, no Paraguai, que modificou radicalmente a paisagem da região leste daquele país, e o da rizicultura irrigada no Pampa uruguaio e argentino, que modificou em muito as relações de trabalho, até então dominadas pela estrutura social tradicional das grandes estâncias de criação extensiva.

A modernização e a integração ao mercado capitalista internacional caminham lado a lado com a reprodução, mesmo do outro lado da fronteira (política), das mesmas práticas excludentes e concentradoras de um capital que, antes de tudo, busca o maior lucro ao menor custo. É assim que, ao lado da reconcentração fundiária, são registrados imensos danos ecológicos: a floresta tropical do leste paraguaio quase desapareceu, inundada pelos campos de soja, e muitas várzeas do interior uruguaio perderam rapidamente sua condição de ecossistemas privilegiados na biodiversidade do Pampa. A vida dos nativos guaranis paraguaios, num relativo equilibrio com o seu meio, é relegada a um segundo plano: cada vez eles ficam mais reclusos nas proximidades das poucas áreas florestais remanescentes, ou alimentam os fluxos migratórios para os principais centros urbanos.

Num mundo em que é cada vez mais rara essa integração entre homem e meio. espaço político, econômico e cultural, como um dia ocorreu no espaço indígena, não é fácil identificar espaços "integradosintegradores", onde a paisagem reflita uma unidade entre as diversas esferas da vida humana. Esta era a leitura feita pelos geógrafos franceses da Geografia mais tradicional, identificando "regiões homogêneas" mundo afora. Hoje é o tempo da mobilidade, da des-integração. da descontinuidade, dos fluxos, enfim, o espaço e o tempo das "redes".

A lógica reticular ou das redes domina nosso cotidiano, ao ponto de alguns autores, como Castells (1999), denominarem a nossa sociedade de "sociedade em rede". Da rede de televisão à rede urbana, da rede de capitais à rede de informações, tudo parece circular e se conectar. Mas o que vemos, na realidade, são redes muito distintas, variáveis conforme o tipo de fluxo que elas movimentam e os grupos ou classes sociais que elas envolvem. Dessa forma, facilmente identificamos quem está efetivamente "conectado" nas redes dominantes, e quem está excluído delas. Entre os excluídos, como é o caso de muitos 
migrantes, pode-se falar mais em desconexão do que em conexão, e eles muitas vezes são obrigados a criar suas próprias redes, "paralelas" (para outros "ilegais"), como forma de resistência ou, simplesmente, de sobrevivência.

\section{A DIVERSIDADE DAS REDES "BRASILEIRAS"}

Entre os brasileiros que migram para os vizinhos do Prata podemos identificar vários tipos de redes, variáveis conforme as classes sociais, os produtos e as informações nelas envolvidas. Como geógrafos, priorizamos as redes geográficas, ou que manifestam uma base espacial, concreta. bastante nítida. Assim, foi possível construir um grande quadro (v. quadro 1 ) em que sintetizamos as redes construídas pelos migrantes, nas mais diversas esferas da vida social, do econômico ao político e ao cultural. Estas redes são vitais na sobrevivência do grupo, mas elas são diferenciadamente vividas, partilhadas, dependendo, sobretudo, da condição sócioeconômica do migrante. Para os mais pobres, muitas dessas redes são construídas e acionadas como uma estratégia (às vezes única) de sobrevivência, para os mais ricos, elas são o veículo da alternância, da opção entre diferentes modos de vida.

Vejamos um exemplo, em relação às redes que envolvem uma conotação política, ligadas à questão formal da cida-
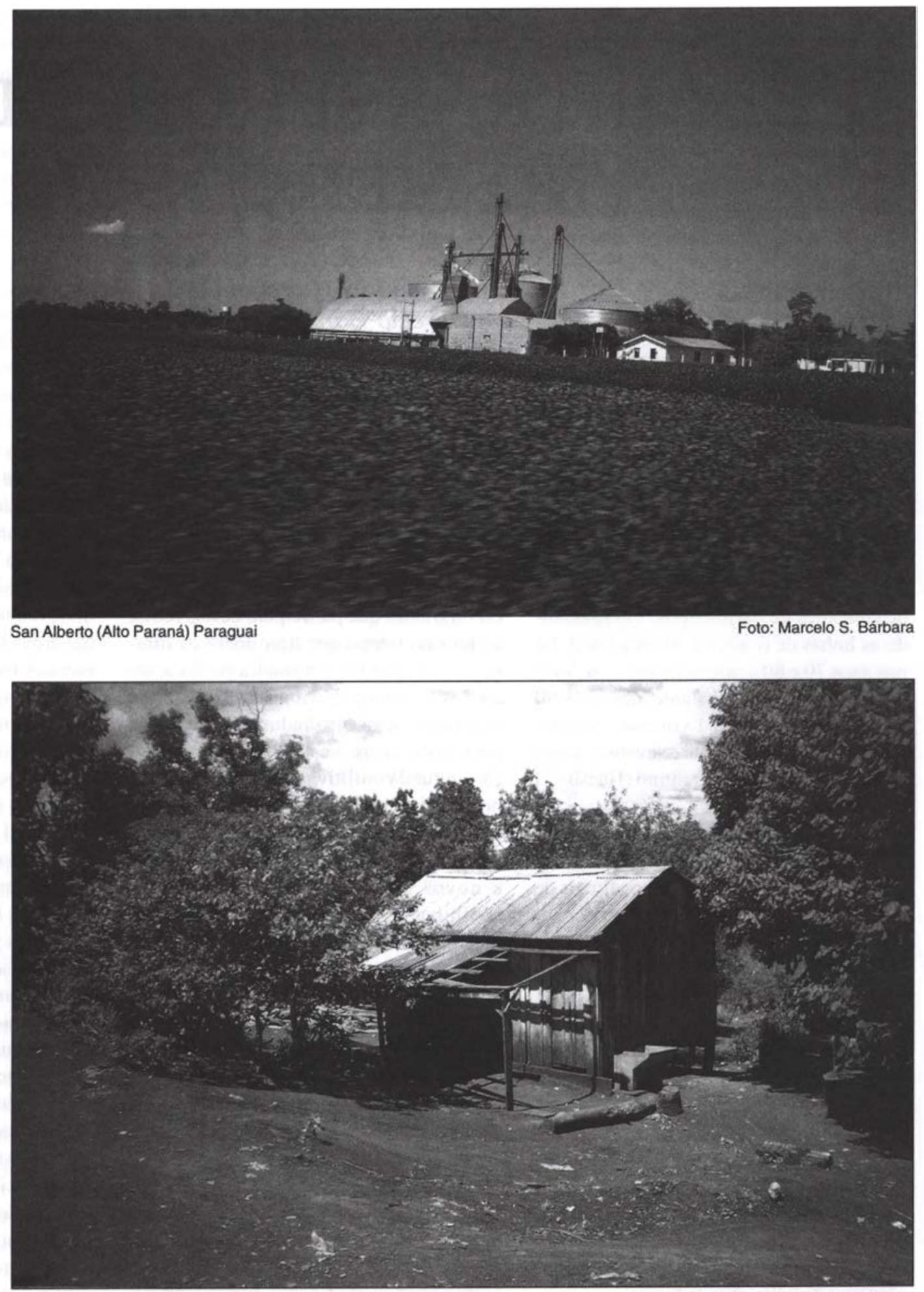

dania. Muitos migrantes brasileiros mantêm seus títulos eleitorais e sua documentação brasileira - mas, ao contrário dos mais ricos, não como uma forma de "dupla nacionalidade". Para o mais pobre, isto está relacionado a um mínimo de garantias sociais numa vida precária, marcada pela difícil legalização de sua situação nos países vizinhos. Muitas vezes, é uma questão de sobrevivência, pois o acesso a algum serviço público em termos de saúde e educação pode, em último caso, com a documentação brasileira, estar acessível do outro lado da fronteira.
Por outro lado, há sempre a esperança de que, se não der certo no país vizinho. resta a possibilidade do retorno, como se a manutenção da nacionalidade brasileira fosse também uma estratégia de resistência. Se for preciso votar num vereador ou deputado no Brasil com a promessa de que 


\section{Quadro 1. REDES TRANSFRONTEIRIÇAS "BRASILEIRAS" NOS VIZINHOS DO MERCOSUL}

\section{TIPOS DE REDES}

\section{Ideológico- culturais}

Parentesco

\section{Movimentos Sociais}

Políticoeleitorais

Serviços

\section{Econômicas \\ (legais)}

Econômicas

(ilegais)

\section{CARACTERÍSTICAS GERAIS}

A manutenção de vínculos de ordem cultural-identitário entre os migrantes brasileiros nos países vizinhos e destes com o Brasil representa um amálgama fundamental na sua manutenção enquanto grupo. A utilização do idioma português e a difusão dos veículos de comunicação brasileiros são instrumentos da reprodução destes laços. Em áreas como San Alberto e Santa Rita, no Paraguai, Colônia Alicia e Colônia Aurora, na Argentina, e Vila Encina, no Uruguai, o português (ou o espanhol "carimbado" pelo português, como dizem os uruguaios) é o principal idioma de comunicação. Além disso, rádios locais têm programaçōes exclusivamente em português (vide a Pioneira 93.5 em San Alberto) e as redes de rádio e televisão brasileiras muitas vezes são mais difundidas que as dos países vizinhos. Em nível de cultura e da identidade regional é muito representativo o avanço do tradicionalismo gaúcho em localidades paraguaias, com Centros de Tradições Gaúchas (CTG) em Santa Rita e San Alberto (aqui com o nome "híbrido" de "Centro de Tradições Guaranis"), vinculados à rede do gauchismo paranaense, pois pertencem à região tradicionalista de Guarapuava, no Paraná.

Grande parte dos migrantes brasileiros mantém fortes laços afetivos e de parentesco com os familiares que vivem, principalmente, na região Sul do Brasil. Muitos laços familiares são mantidos pela continuidade dos casamentos com habitantes das áreas de origem do migrante. São constantes, também, as viagens transfronteiriças, nos dois sentidos.

Redes de movimentos sociais também se articulam como redes transfronteiriças. É marcante a atuação do Movimento dos Trabalhadores Sem Terra (MST) e da Pastoral do Migrante, especialmente no Paraguai. Diversos representantes do MST, em La Paloma e San Alberto, têm orientado e encaminhado "brasiguaios" para acampamentos no oeste do Paraná e sul do Mato Grosso do Sul. A Pastoral do Migrante, baseada em Foz do Iguaçu (PR), atua na obtenção de carteiras de imigração e apoio jurídico para brasileiros ilegais no Paraguai. Também há contatos entre o MST e a associação de pequenos produtores argentinos. Fazendeiros uruguaios revelam temor com a possibilidade da entrada do MST no país. a partir de Bagé (RS).

Muitos imigrantes mantêm o título eleitoral brasileiro. Existem milhares de eleitores que, embora residam em território paraguaio, argentino ou uruguaio, continuam votando no Brasil. Em Foz do Iguaçu calcula-se que cerca de 10 mil "brasiguaios" venham participando das eleições (A Gazeta do Iguaçu, 10/09/1996). Muitos vereadores no Brasil (em cidades como Foz do Iguaçu - PR e Dionísio Cerqueira - SC) são eleitos graças a promessas feitas a migrantes brasileiros no Paraguai e na Argentina, oferecendo assistência médica em hospitais ou vagas em escolas.

É muito comum os migrantes recorrerem aos serviços de educação e saúde no Brasil, principalmente no caso paraguaio, onde estes serviços geralmente são mais precários, gerando assim fluxos temporários bastante intensos ao longo da fronteira. Por outro lado, a condição de dupla cidadania torna-se uma estratégia para o usufruto de benefícios como os financiamentos à produção, ora demandados em território brasileiro, ora no país vizinho. Muitos também, mesmo residindo no outro país, têm aposentadoria e benefícios previdenciários garantidos pelo Estado brasileiro.

Estas talvez sejam as redes de caráter transfronteiriço mais antigas, e que independem da figura do migrante para se fortalecerem. Envolvem o intercâmbio de produtos, incrementado em muito com a criação do Mercosul, alguns dos quais diretamente ligados à presença da migração brasileira (especialmente a soja, no caso paraguaio, o arroz, no caso argentino e uruguaio, e, nos três países, o gado). Muitas vezes são os mesmos empresários brasileiros que possuem estabelecimentos (empresas ou cooperativas) dos dois lados da fronteira. No caso do pampa argentino-uruguaio é um processo bastante antigo e que envolve inclusive figuras conhecidas do mundo político, como João Goulart e Leonel Brizola. Ressaltem-se também os circuitos financeiros, cada vez mais pronunciados, envolvendo aqui tanto operações legais quanto ilegais.

Muitos migrantes, sem outra alternativa, acabam se envolvendo com o tráfico de várias tipos, comandado através de redes hierarquizadas que chegam até a escala global. Destacam-se o contrabando de drogas, madeiras, produtos agrícolas, automóveis, etc. O rio Paraná, via lago da represa de Itaipu, é o espaço mais utilizado pela contravenção e o crime organizado entre o Brasil e o Paraguai. Outra rede ilegal que envolve máfias brasileiro-paraguaias é a da prostituição. No caso argentino. com presença maior de reservas florestais ao longo da fronteira, é freqüente o contrabando de madeiras-de-lei através de rios como o Peperi-Guaçu e o Uruguai. Produtos valorizados nos dois lados da fronteira, como o arroz (produzido no Uruguai e Argentina) e a soja (produzida no Paraguai), também participam de redes de comércio ilegal. É conhecido o caso da soja brasileira contrabandeada para o Paraguai e que volta para ser exportada como soja paraguaia pelos portos brasileiros. 
uma vaga na escola ou a assistência hospitalar será garantida, a rede transfronteiriça pode ser acionada. Já houve casos em que a ponte da Amizade, entre o Brasil e o Paraguai, foi interditada em dia de eleições para evitar a "procissão" de políticos brasileiros patrocinando transporte para os eleitores do outro lado da fronteira. O povo humilde sendo usado, mais uma vez, como massa de manobra.

Por sua vez, entre os que têm uma situação econômica mais estruturada, e que têm acesso a crédito bancário, como o migrante brasileiro Paulo (nome fictício), que entrevistamos em San Vicente, na província argentina de Misiones, manter a nacionalidade brasileira, mesmo já tendo conseguido a argentina, representa a possibilidade de buscar financiamentos tanto nos bancos argentinos quanto no Banco do Brasil, driblando assim, um pouco, as vicissitudes das conjunturas econômicas - ou, no caso dos mais ricos, conseguindo uma lucratividade muito maior.

Há redes que prescindem do deslocamento físico do migrante. Não são propriamente "redes de migrantes", mas servem como pano de fundo para moldar vários comportamentos sociais. As redes de televisão, por exemplo, que não precisam de uma infra-estrutura física contínua para se expandirem, alcançam facilmente o lado paraguaio, uruguaio e argentino da fronteira, e entram "sem pedir licença". Assim, vemos muitas famílias uruguaias assistindo a rede Globo e envolvendo-se, indiretamente, com problemáticas e práticas culturais do lado brasileiro. Quanto aos migrantes brasileiros, entre eles a televisão representa um importante amálgama de manutenção da coesão sócio-cultural. Não há dúvida que, desta forma, desenhase um "subimperialismo" cultural brasileiro transfronteiriço, e que a retomada de identidades fortes, como a guarani, no Paraguai, pouco tem conseguido suplantar.

A própria identidade do migrante acaba refletindo esta condição de "habitante transfronteiriço", como se ele não estivesse nem de um lado, nem de outro, não fosse nem brasileiro, nem paraguaio. Como se ele, numa visão extrema, habitasse mais a rede (transfronteiriça) do que o território (nacional) bem delimitado. Assim, fi- guras como a do brasiguaio, que na origem significava apenas o brasileiro que não conseguiu terras no Paraguai e retornou ao Brasil em busca da sobrevivência, transformaram-se em identidades mais gerais dos migrantes brasileiros no exterior, reveladoras dessa condição ambivalente, de indivíduo com dois territórios, um indivíduo dividido, inseguro, mas também, por outro lado, dependendo da situação, um indivíduo que dispõe de estratégias múltiplas de sobrevivência. Sua condição de participante (mesmo eventual) de uma rede transfronteiriça constitui uma espécie de "capital" a que ele pode recorrer, dependendo das circunstâncias.

Transgredindo os limites do Estado nação, o migrante dessas redes transfronteiriças, "brasiguaio" ou "brasentino", pode ser visto como "aquele que vive dos dois lados da fronteira". Como dizem muitos pesquisadores, é a rede que permite compreender melhor os processos sociais contemporâneos, por manifestar a ambivalência, a flexibilidade e, ao mesmo tempo, a insegurança do nosso tempo. A rede revela o caráter dinâmico, o mundo de relações mutáveis em que estamos mergulhados, e supera a antiga idéia de identidades fixas, refletidas num território bem definido.

Mas nunca podemos esquecer que a rede em si não é um agente ou um sujeito, mas apenas uma forma ou um veículo pelo qual ser realizam relações sociais. Por trás (ou por dentro) dela encontram-se os verdadeiros atores: capitalistas, políticos, intelectuais, migrantes, refugiados. Por isso, nem todas as redes são "abertas", "flexíveis", veiculadoras da multiplicidade que os ricos dizem usufruir. $\mathrm{Na}$ fronteira do Brasil com os vizinhos do Mercosul podemos identificar redes transfronteiriças de diversas ordens, desde aquelas que representam uma maior maleabilidade para o migrante, até aquelas que, ao contrário, reforçam sua fragilidade e sua dependência (como as redes do contrabando, da prostituição, do narcotráfico). Cabe-nos analisar e, de alguma forma, estimular aquelas redes através das quais o migrante efetivamente se organiza, se fortalece e se autonomiza enquanto grupo, enquanto indivíduo e enquanto ser humano.
* Rogério Haesbaert é doutor e professor de Geografia da Universidade Federal Fluminense.

** Marcelo de Jesus Santa Bárbara é licenciado e mestre em Geografia pela mesma Universidade.

\section{NOTAS}

1. Trata-se da pesquisa "A Regiāo frente aos processos de Globalização e Fragmentação: a formação de uma regiăo transfonteiriça entre os paises vizinhos do Mercosul", com auxilio do CNPq e coordenada por Rogério Haesbaert. Marcelo Santa Bárbara foi bolsista de iniciação científica neste projeto e realizou dissertação de mestrado sobre o tema da identidade brasiguaia.

2. José de Souza Martins (1997:150) afirma que "o que há de socialmente mais relevante para caracterizar e definir a fronteira no Brasil é (...) a situaçāo de conflito" e, "nesse conflito, a fronteira é essencialmente o lugar da alteridade", do encontro com os outros - como os indios e os camponeses pobres.

\section{REFERÊNCIAS BIBLIOGRÁFICAS}

\section{CASTELLS, $M$.}

(1999) A sociedade em rede. Rio de Janeiro, Paz e Terra.

HAESBAERT, R. e SILVEIRA, M.

(1999) Migração brasileira no Mercosul. Travessia-Revista do Migrante, $n^{2} 33$, janeiro-abril, p.5.

KOHLHEPP, G.

(1982) "Problems of dependent regional development in Eastern Paraguay with special relevance to brazilian influence in the pioneer zone of the Amambay plateau". Applied Geography and Development $n^{\circ} 22$, Tũbingen.

MARTINS, J. de S.

(1997) Fronteira: a degradação do Outro nos confins do humano. São Paulo, Hucitec.

SANTA BÁRBARA, M.

(2001) Des-caminhos brasileiros em terras paraguaias: territórios e jogos de identidades. Dissertação de Mestrado, UFF.

SOUCHAUD, $S$.

(2000) La formation d'un espace "bresiguayen" dans l'est du Paraguay: Migracion pionnières brésiliennes et organizations socio-espatiales dans l'oriente du Paraguay. Tese de Doutorado, Univ. de Poitiers.

SPRANDEL, $M$.

(1992) Brasiguaios: Conflitos e Identidades em Fronteiras Internacionais. Tese de Mestrado, Rio de Janeiro, Museu Nacional. 